\title{
Evolução do comércio intraindustrial entre Brasil e Estados Unidos no período 1997 - 2008
}

\author{
Tânia Moreira ${ }^{1}$ \\ Nilson de Paula ${ }^{2}$
}

Resumo: Ao final dos anos de 1980 o Brasil alterou o perfil de suas relações comerciais tornando-se exportador, predominantemente, de produtos manufaturados. Os EUA têm tido um grande peso nessa alteração, por ser um importante parceiro comercial, especialmente de produtos manufaturados. Dados por fator agregado indicam um grande volume de comércio de produtos manufaturados, sugerindo fortes relações intraindustriais entre os dois países. Este trabalho tem por objetivo analisar a intensidade dos fluxos de comércio intraindustrial entre Brasil e EUA no período 1997 - 2007, utilizando para isto o índice de Grubel \& Lloyd a nível de dois e quatro dígitos, segundo a nomenclatura NCM. Nesta análise foram destacados os produtos que apresentaram índices iguais ou superiores a 0,7, e que representam a maior proporção do valor do comércio entre os dois países. Baseado nesses parâmetros, concluiu-se que, embora o comércio interindustrial predomine num grande número de produtos, o maior valor da corrente de comércio, ao longo do período analisado é sustentado por relações de troca intraindustriais.

Palavras-chave: Comércio bilateral; Comércio intraindustrial; Relação Brasil EUA.

\section{Intra-industrial trade evolution between Brazil and the United States of America from 1997 to 2008}

\footnotetext{
Abstract: By the end of the 1980's Brazil changed the profile of its commercial relationships becoming mainly an exporter of manufactured products. The US, being an important trade partner has played a big role on that change, especially regarding manufactured products, whose evidence has suggested a growing weight

1 Bacharel em Economia pela Universidade Federal do Paraná - Economista da Federação da Agricultura do Estado do Paraná. Email: taniamoreira@ufpr.br

2 Professor Titular do Departamento de Economia da Universidade Federal do Paraná. Email: nilson@ufpr.br
} 
of an intra-industry relationship between the two countries. This paper aims at assessing the intensity of that trade pattern between Brazil and USA from 1990 to 2007 through the Grubel - Lloyd index at the level of two and four digits following the NCM nomenclature. This analysis has highlighted products with Grubel Lloyd index equal to or higher than 0.7 , related to those products whose value comprises more than 70\% of the total commercial flow between Brazil and USA. Despite the trade of many items is described by inter-industry relations, most of the value exchanged between these two countries, throughout the years under scrutiny, is increasingly defined in terms of intra-industry trade, given the analysis of specific groups of product.

Keywords: Bilateral Trade; Intra-industrial trade; Brazil - US trade relations.

JEL: F14

\section{Introdução}

Durante a evolução da economia mundial nos últimos cinquenta anos, várias economias antes tipicamente exportadoras de matérias primas passaram a se destacar no comércio de produtos industrializados, com base em vantagens competitivas criadas alterando, com isso, seu perfil exportador. A economia brasileira, a partir do final dos anos de 1970, se destacou nessa tendência, em consequência de mudanças estruturais decorrentes de sua estratégia de industrialização adotada desde o pós-guerra. Essa trajetória foi estimulada pelo grande peso da economia dos EUA nas relações comerciais brasileiras, nas quais o padrão de comércio bilateral se tornou gradativamente intraindustrial. Essa evolução foi mais perceptível em determinados grupos de produto, cuja complexidade produtiva e tecnológica se estende ao interior das duas economias.

Tendo por base as evidências do comércio por fator agregado, o objetivo deste artigo é analisar a dimensão do comércio intraindustrial, tendo como base as características dos produtos comercializados e o grau de complementaridade entre Brasil e Estados Unidos no período de 1997 a 2008. Para tanto é utilizado o índice de Grubel \& Lloyd para identificar o nível de integração intraindustrial, a partir dos dados de comércio extraídos da base Alice Web relativos à composição da pauta de exportação e importação, em nível de dois dígitos, de acordo com a Nomenclatura Comum do Mercosul (NCM). Para tanto, o campo de observação desta análise está concentrado nos setores industriais de maior peso na corrente de comércio.

O referencial de análise, apresentado no item 2, consiste numa revisão das teorias de comércio, com destaque para o conceito de comércio intraindustrial e sua emergência no interior das teorias de comércio a partir das reconhecidas fragilidades dos modelos baseados em produtividade e dotação de fatores. No item 3 é discutida a evolução do comércio entre Brasil e Estados Unidos 
no período após 1990, com ênfase nos anos de 1997 a 2008 e nos grupos de produtos a dois dígitos cujos índices de comércio intraindustrial estiveram acima de 0,5 e nos quais a densidade tecnológica é mais elevada. Por fim, são apresentadas as conclusões da análise.

\section{Um referencial para análise do comércio intraindus- trial}

As análises sobre o comércio internacional, em geral, têm como ponto de partida a teoria clássica, mais especificamente a teoria ricardiana dos custos comparativos e as sucessivas adaptações de seus princípios. Nessa trajetória destaca-se a teoria de proporção de fatores e consequente equalização de seus preços $^{3}$. O arsenal de modelos construídos para adaptar os princípios clássicos ao comércio internacional do pós-guerra, ainda mantinha entre os principais pressupostos, concorrência perfeita, ganhos mútuos de bem estar, alocação ótima dos recursos produtivos, e falta de mobilidade internacional de fatores. Sendo os países deslocados para posições distintas na divisão internacional do trabalho, as trocas internacionais seriam tipicamente interindustriais, resultantes das suas diferenças estruturais e estáticas. Em outras palavras, essa base teórica tinha maior aderência no comércio entre o Norte industrializado e desenvolvido e o Sul subdesenvolvido e exportador de matérias primas e produtos de baixo grau de processamento.

Entretanto, já a partir de meados dos anos de 1960, o comércio internacional passa a refletir condições produtivas típicas de concorrência imperfeita, com ganhos de escala e fortalecimento de oligopólios, da internacionalização dos investimentos, da emergência de novos países competidores, de uma nova revolução tecnológica, etc. Ao associar o padrão de comércio com o perfil da demanda doméstica, Linder (1961), é pioneiro na detecção do comércio intraindustrial, realçando a inadequação da teoria das vantagens comparativas para explicar o comércio que emergiu no pós-guerra. Simultaneamente, ao entrar na agenda dos países subdesenvolvidos, a industrialização forçou-os a uma gradativa convergência estrutural aos países de industrialização antiga.

Posteriormente, o escopo das teorias do comércio passou a incorporar tanto aspectos macroeconômicos como PIB, renda per capita e perfil da demanda, de cada país, quanto microeconômicos como economias de escala, diferenciação do produto e inovação tecnológica (Greenaway \& Winters 1994). Quanto mais semelhantes os países forem em termos de renda e de padrão de consumo, mais intensa tende a ser a troca de produtos dotados das mesmas características, como sugere o conceito de demanda representativa de Linder. Para Greenaway e Tharakan (1986), essa interpretação implica em diferenciação de

3 Uma extensa, embora objetiva, revisão das contribuições feitas às teorias clássicas de comércio, pode ser vista em artigo originalmente publicado em 1955 por Harbeler, G. e reproduzido por Savasini, J.A.A, P. Malan e W. Baer (1979) 
produtos e, portanto, num padrão de comércio mais intenso entre países com rendas per capta semelhantes. Considerações sobre a demanda interna dos países exportadores foram retomadas por Krugman $(1979,1980)$ ao realçar o "home market effect", segundo o qual os países tendem a exportar bens para os quais há um extenso mercado interno.

Nesse contexto, o ciclo do produto desenhado por Vernon (1966) colocou em evidência, de forma pioneira, a inter-relação, e suas pré-condições, entre investimento estrangeiro e comércio, características tecnológicas dos produtos, e nível de desenvolvimento econômico dos países. O processo de convergência das economias, em termos de renda, população, nível de desenvolvimento industrial, etc., fez com que o comércio refletisse crescentemente similaridades entre os países. Dessa forma as hipóteses clássicas relacionadas à produtividade do trabalho, abundância dos fatores e intensidade de seu uso, foram revisadas e ajustadas numa abordagem segundo a qual o padrão de comércio internacional se dá entre estruturas produtivas semelhantes (Markunsen \& Venables 2000). Assim, à pergunta básica sobre porque os países comercializam, novas respostas surgiram no âmbito da nova teoria do comércio, construída em torno da concorrência imperfeita, ganhos de escala e diferenciação de produtos (Krugman 1980, 1981; Helpman 1981), mesmo que seus pressupostos estejam enquadrados nos modelos estáticos de concorrência monopolista de Chamberlain (Fontagné \& Freudenberg 1997). Portanto, a crescente incapacidade das teorias de inspiração ricardiana para explicar a evolução do comércio internacional após os anos de 1960, e a emergência da nova teoria do comércio, deslocaram as causas do comércio para outros determinantes. Diante da constatação de que países com dotações semelhantes de fatores aumentaram o volume de comércio entre si, as críticas ao então dominante modelo de Heckscher-Ohlin ganharam volume e consenso com a chamada nova teoria do comércio.

De acordo com Loertscher e Wolter (1980), o comércio intraindustrial entre os países tem relação direta com o estágio de desenvolvimento, o tamanho do mercado interno de cada país, e as barreiras existentes ao comércio. Se os estágios de desenvolvimento dos países que comercializam são elevados, se seus mercados internos são amplos e as barreiras ao comércio são baixas, o fluxo de comércio intraindustrial tende a ser mais intenso. Igualmente, para Helpman (1987) quanto mais semelhantes são os países em termos de PIB e PIB per capta, mais intenso seria o comércio intraindustrial entre eles.

Como sugerido acima, a crescente complexidade das relações comerciais a partir de meados dos anos de 1970 esteve fortemente relacionada às economias de escala - internas e externas - e aos processos de inovação tecnológica, incorporados na análise microeconômica pelos modelos de concorrência imperfeita. Segundo o modelo de concorrência monopolista desenvolvido a partir de Chamberlain, as firmas se comportam como monopólios por terem a possibilidade de diferenciar seus produtos e de explorar economias de 
escala internas, resultando em custos médios decrescentes (Greenaway \& Winters 1994). Nessas condições, mesmo que as economias de escala internas, típicas da produção de commodities, possam se distanciar de relações intraindustriais, as economias externas se revelam propulsoras deste padrão de comércio, por se proliferarem em ambientes empresariais, onde segmentos de uma mesma indústria convivem, produzindo produtos diferenciados e complementares. Isso não elimina, todavia, estruturas de mercado concentradas.

Segundo os pressupostos de concorrência imperfeita, mesmo que especialização e comércio intraindustrial sejam proporcionados por economias de escala internas, estruturas de mercado de baixa concentração, onde predominam economias de escala externas, não podem ser excluídas. Neste caso, o produto da indústria tende a ser mais diversificado, como tal ampliando o espectro de bens comercializados, enquanto as economias de escala internas se associam com produtos homogêneos e, portanto, um padrão de comércio tipicamente interindustrial. Por outro lado, decisões de IDE através de expansão horizontal da firma, estimulam um comércio intraindustrial, na medida em que a replicação de plantas industriais em diferentes países leva a transações intrafirma de produtos semelhantes. Mesmo assim, é possível que o comércio derivado de uma expansão vertical da firma se caracterize como interindustrial, a partir das trocas de componentes e produtos acabados.

De maneira geral, há uma relação ambígua entre as economias de escala, uma vez que as economias internas podem ser uma das causas do comércio intraindustrial, enquanto as economias externas o reforçam. Isto porque estas últimas estão associadas a produtos diferenciados, trocados dentro de uma mesma indústria, que mesmo desfrutando das vantagens da aglomeração espacial, exploram os mercados globais (Krugman 1994).

Adicionalmente, o comércio intraindustrial é alimentado pela inovação tecnológica a partir dos gaps tecnológicos entre os países. A incorporação de conhecimentos tecnológicos determinaria as vantagens competitivas e o modo de inserção internacional de um país. Manter o poder de mercado, como no caso das firmas em concorrência imperfeita, e sustentar um padrão de comércio depende da capacidade de manter o processo de inovação e de catching up através da imitação e do aprendizado. Uma mudança tecnológica num país poderá levar outros a imitá-la, reduzindo o gap, elevando os níveis de renda e diversificando o padrão de consumo diferenciado. Além disso, a capacidade das firmas de diferenciar seus produtos está relacionada - além da redução de custos - com a capacidade de introduzir inovações tecnológicas, adaptando os produtos aos mercados locais dos diversos países, como acontece no comércio intrafirma. (Dosi, Pavitt \& Soete 1990).

Embora o comércio intrafirma possa ser explicado pelas estratégias de transferências de preço e pelas vantagens oriundas das diferenças internacionais de regimes de regulamentação e impostos, sua determinação principal está na especificidade dos fatores da indústria e na capacidade das firmas desenvolverem 
tecnologias específicas. O poder de inovação e diferenciação de produtos daí resultante reforça estratégias de integração horizontal e consequentemente, relações de comércio intraindustrial no interior da firma.

Tendo em vista os aspectos acima mencionados, o comércio interindustrial é determinado pela dotação dos fatores, diretamente associado às vantagens comparativas. Por sua vez, o comércio intraindustrial está ligado a economias de escala e diferenças em termos da relação capital/trabalho e grau de inovação tecnológica embutida nos produtos comercializados. Entretanto, a distinção entre eles está sujeita a vários obstáculos oriundos dos procedimentos envolvidos no nível de desagregação dos dados utilizados para sua análise. Considerando uma indústria como um todo, todas as transações em curso serão enquadradas na condição de comércio intraindustrial. Por outro lado, se a análise se basear num nível detalhado de produtos, digamos 4 dígitos, o comércio interindustrial será predominante, mesmo que ocorrendo no interior de um mesmo setor de atividade. "For what it's worth, the formal models allow for only two levels of aggregation: the industry as a whole, for which intra-industry trade is an indicator of the role of scale economies, and the level of individual differentiated products, for which there ought to be no intra-industry trade." (Krugman 1993:18)

A extensão do comércio intraindustrial pode ser calculada através do índice de Grubel e Lloyd:

$\mathrm{I}=1-\sum|\mathrm{Xi}-\mathrm{Mi}| / \sum(\mathrm{Xi}+\mathrm{Mi})$

Sendo I o índice de sobreposição das trocas entre os países, Xi e Mi respectivamente, as exportações e importações do país sede da indústria produtora do produto i. Se o índice for igual a zero, o comércio será caracterizado por uma completa especialização internacional, na qual o país será importador ou exportador de produtos da indústria i. Se o índice for igual a 1 o país será exportador e importador de produtos de uma mesma indústria. Segundo o conceito original, o índice é definido pela compensação entre o valor das exportações e importações de uma mesma indústria (Grubel \& Lloyd 1975).

Mesmo diante da grande relevância desse conceito, sua aplicação pode levar a resultados contraditórios, dependendo do grau de agregação dos dados analisados. Quando este é muito elevado, o índice de comércio intraindustrial pode ser superestimado. Por outro lado, dados muito desagregados podem resultar num índice de comércio intraindustrial subestimado, mesmo que os produtos pertençam a uma mesma indústria. Essa aparente contradição, todavia não diminui a importância do padrão de comércio como um instrumento para a análise das relações comerciais, especialmente quando referidas a trocas bilaterais.

Vasconcelos (2003) analisou o crescimento do fluxo de comércio após a formação do MERCOSUL, identificando o peso das trocas de caráter intraindustrial nas transações entre Brasil e demais países do bloco. Da mesma forma Hidalgo 
(1993) havia analisado o perfil das exportações brasileiras de produtos manufaturados durante os anos de 1980, visando identificar os impactos causados pelas mudanças na política comercial liberalizante no ocaso da estratégia de substituição de importações. As transações com os produtos mais afetados pela nova estratégia comercial do país foram analisadas à luz do conceito de comércio intraindustrial. Silva (2002) investigou o alcance do comércio intraindustrial na análise das transações bilaterais entre Brasil e Argentina durante o período de 1989 a 2002. Da mesma forma, Caldarelli e Miranda (2009) analisaram, utilizando o modelo LOGIT, a evolução do comércio intraindustrial entre Brasil e China no período de 1990 a 2007, frente à imposição de barreiras não tarifárias pelo governo chinês. O protecionismo tende, segundo concluem, a se elevar na medida em que o padrão de comércio intraindustrial evolui positivamente.

As evidências identificadas e discutidas nos vários estudos sobre comércio, em particular no plano bilateral, apontam para uma visível importância de trocas intraindustriais. Todavia, guardadas as diferenças entre países e regiões, esse movimento deve ser visto no contexto da maior integração da economia mundial, em especial das estratégias de investimento direto estrangeiro por parte das grandes corporações multinacionais. A descoberta e exploração de vantagens competitivas no âmbito mundial têm levado muitas economias a ocuparem novas posições no mercado mundial. Com isso as relações comerciais vão, gradativa e obrigatoriamente, convergindo numa direção onde os produtos manufaturados derivam de estratégias produtivas similares de ganho de escala, diferenciação de produtos e suprimento internacional de componentes. Adicionalmente, essa tendência é reforçada pelo peso da corrente de comércio no PIB de cada país. Quanto mais amplo o grau de abertura das economias maior a probabilidade de suas relações comerciais com o resto do mundo assumirem um padrão intraindustrial (OECD 2002).

Nesses termos, o comércio entre Brasil e Estados Unidos é tido como emblemático, quando analisado no longo prazo, não apenas pela grande importância que o mercado americano tem para as exportações brasileiras, tendo alcançado mais de um terço no início dos anos de 2000. Mais do que isso, como amplamente demonstrado pela literatura sobre o desenvolvimento industrial brasileiro, o fato de o Brasil ter passado por um profundo processo de industrialização o levou a superar sua condição de país exportador de produtos de baixo grau de processamento e de matérias primas. Consequentemente, a economia brasileira traçou uma linha de convergência em relação à economia daquele país a partir do desenvolvimento competitivo de diversos setores industriais.

\section{Padrão de comércio entre Brasil e Estados Unidos}

A evolução do padrão de comércio sustentado pela economia brasileira tem sido um objeto de análise abraçado por vários autores, especialmente na medida em que o processo de industrialização avança e se diversifica. Entre- 
tanto, mais do que identificar a composição das exportações e importações, crescente atenção tem sido dada ao perfil das trocas com o resto do mundo.

Em que pese uma notória diversificação de mercados externos da economia brasileira, os Estados Unidos, mesmo reduzindo sua importância como um parceiro comercial histórico da economia brasileira, ainda se destaca como destino de mais de um terço das exportações brasileiras. No tocante à pauta de produtos exportados, os EUA se destacam prioritariamente como destino de manufaturas, enquanto as commodities agropecuárias têm crescentemente predominado nas exportações para a União Europeia, outro parceiro comercial relevante da economia brasileira (WTO 2007). Frente ao pronunciado perfil agroexportador nas relações com a UE, tem ocorrido um forte fluxo de importação de produtos industrializados daquele continente.

Já as relações comerciais com os EUA, objeto da análise aqui desenvolvida, refletem um grau de complementaridade mais visível envolvendo exportações de produtos industriais e importações de produtos intermediários e bens de capital. Assim, as relações comerciais entre Brasil e EUA guardam uma simultaneidade entre padrões de comércio inter e intraindustrial, tendo em vista a maior intensidade de trocas no âmbito das manufaturas. Ou seja, as economias comercializam produtos de uma mesma categoria - manufaturados - porque produzem produtos diferenciados a partir de uma complexa estrutura industrial marcada por ganhos de escala interna e externa e intenso fluxo de inovação tecnológica.

\section{GRÁFICO 1}
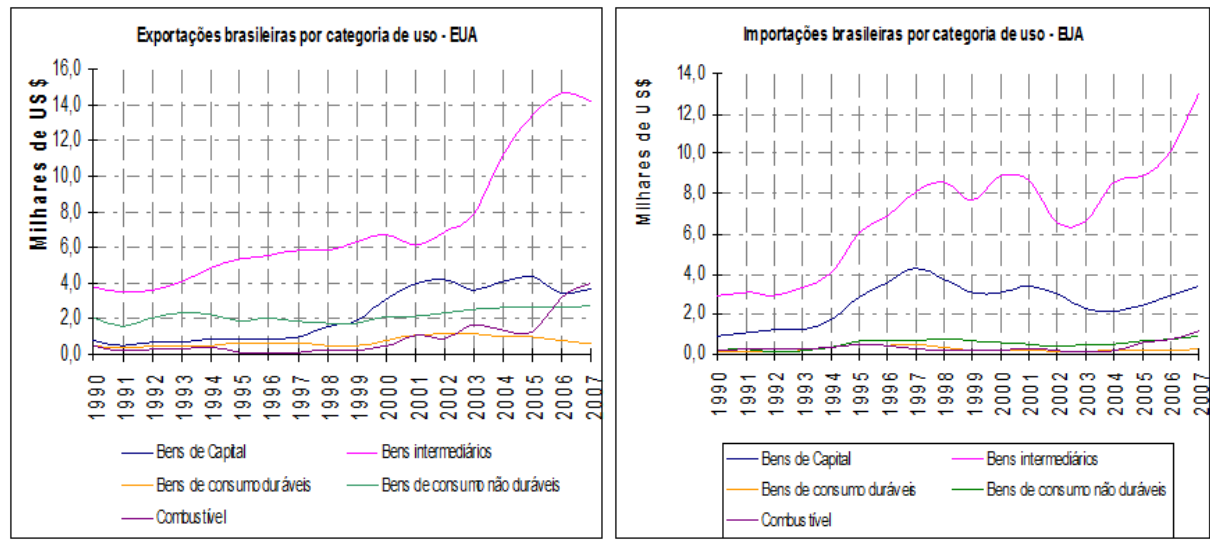

FONTE : FUNCEX - Elaboração própria

Desta forma, o comércio entre Brasil e EUA parece ser caracterizado por uma relação de complementaridade, na qual os produtos são de uma mesma categoria, embora não necessariamente os mesmos. Por exemplo, o Brasil exporta máquinas e aparelhos para fabricação de papel ou cartão e importa dos EUA, 
bobinadoras-esticadoras para acabamento de papel ou cartão, os quais, mesmo não sendo necessariamente os mesmos, fazem parte de um mesmo grupo composto por máquinas, aparelhos e instrumentos mecânicos e suas partes. Embora sejam todos manufaturados, os produtos comercializados não concorrem entre si, mas são partes diferentes a serem utilizadas na produção de outros produtos.

Nesse nível de agregação, segundo a Nomenclatura Comum do Mercosul (NCM) ${ }^{4}$, setores industriais mais complexos, do ponto de vista tecnológico, apresentam uma significativa participação na corrente de comércio entre os dois países (Quadro 1).

QUADRO 1. PARTICIPAÇÃO DAS SEÇÕES DE PRODUTO, SEGUNDO A NCM, NA CORRENTE DE COMÉRCIO ENTRE BRASIL E EUA, MÉDIAS TRIENAIS DE 1997 A 2008, EM \%.

\begin{tabular}{|c|c|c|c|c|}
\hline SEÇÃO & $\begin{array}{l}19971 \\
1999\end{array}$ & $\begin{array}{l}2000 / \\
2002\end{array}$ & $\begin{array}{l}2003 / \\
2005\end{array}$ & $\begin{array}{l}2006 / \\
2008\end{array}$ \\
\hline Animais vivos e produtos do reino animal & 0.5 & 0.8 & 0.8 & 0.6 \\
\hline Produtos do reino vegetal & 3.6 & 1.7 & 2.2 & 2.3 \\
\hline $\begin{array}{l}\text { Gorduras e óleos animais ou vegetais; produtos da sua } \\
\text { dissociação; gorduras alimentares elaboradas; ceras de } \\
\text { origem animal ou vegetal }\end{array}$ & 0.2 & 0.1 & 0.1 & 0.1 \\
\hline $\begin{array}{l}\text { Produtos das indústrias alimentares; bebidas, líquidos } \\
\text { alcoólicos e vinagres; fumo (tabaco) e seus sucedâneos } \\
\text { manufaturados }\end{array}$ & 3.4 & 2.6 & 3.4 & 4.9 \\
\hline Produtos minerais & 3.8 & 5.3 & 7.4 & 11.6 \\
\hline Produtos das indústrias químicas ou das indústrias conexas & 12.3 & 10.9 & 11.4 & 12.0 \\
\hline Plásticos e suas obras; borracha e suas obras & 5.0 & 4.2 & 4.4 & 5.2 \\
\hline $\begin{array}{l}\text { Peles, couros, peleteria (peles com pelo*) e obras destas } \\
\text { matérias; artigos de correeiro ou de seleiro; artigos de viagem, } \\
\text { bolsas e artefatos semelhantes; obras de tripa }\end{array}$ & 0.5 & 0.6 & 0.7 & 0.8 \\
\hline $\begin{array}{l}\text { Madeira, carvão vegetal e obras de madeira; cortiça e suas } \\
\text { obras; obras de espataria ou de cestaria }\end{array}$ & 1.8 & 2.3 & 4.1 & 3.2 \\
\hline $\begin{array}{l}\text { Pastas de madeira ou de matérias fibrosas celulósicas; papel } \\
\text { ou cartão de reciclar (desperdícios e aparas); papel e suas } \\
\text { obras }\end{array}$ & 3.5 & 2.8 & 2.5 & 2.6 \\
\hline Materiais têxteis e suas obras & 1.9 & 1.8 & 2.2 & 1.6 \\
\hline $\begin{array}{l}\text { Calçados, chapéus e artefatos de uso semelhante, guarda- } \\
\text { chuvas, Guarda-sóis, bengalas, chicotes, e suas partes; penas } \\
\text { preparadas e suas obras; flores artificiais; obras de cabelo }\end{array}$ & 4.2 & 4.1 & 3.3 & 1.9 \\
\hline $\begin{array}{l}\text { Obras de pedra, gesso, cimento, amianto, mica ou de matérias } \\
\text { semelhantes; produtos cerâmicos; vidro e suas obras }\end{array}$ & 1.1 & 1.4 & 2.4 & 2.7 \\
\hline $\begin{array}{l}\text { Pérolas naturais ou cultivadas, pedras preciosas ou } \\
\text { semipreciosas e semelhantes, metais preciosos, metais } \\
\text { folheados ou chapeados de metais preciosos e suas obras; } \\
\text { bijuterias; moedas }\end{array}$ & 1.6 & 1.4 & 1.5 & 2.0 \\
\hline
\end{tabular}

(Quadro 1 - continua)

4 Segundo informações do Ministério de Desenvolvimento, Indústria e Comércio, de 1990 a 1996 o Brasil utilizava a Nomenclatura Brasileira de Mercadorias - NBM, que adotava dez dígitos para a identificação das mercadorias. A partir de 1996, Brasil, Argentina, Paraguai e Uruguai passaram a utilizar a Nomenclatura Comum do Mercosul - NCM, composta por oito dígitos. Ambas classificações têm por base o Sistema Harmonizado de Designação e de Codificação de Mercadorias - SH, formado por seis dígitos, classificando as mercadorias de acordo com as especificidades dos produtos, tais como origem, matéria constitutiva e aplicação. Com isso há um ordenamento crescente de acordo com o nível de sofisticação das mercadorias abrangendo 21 seções, compostas por 96 capítulos. 
(Quadro 1 - continuação)

\begin{tabular}{|l|c|c|c|c|}
\hline Metais comuns e suas obras & 9.0 & 8.1 & 10.7 & 11.0 \\
\hline $\begin{array}{l}\text { Máquinas e aparelhos, material elétrico, e suas partes; } \\
\text { aparelhos de gravação ou de reprodução de som, aparelhos } \\
\text { de gravação ou de reprodução de imagens e de som em } \\
\text { televisão, e suas partes e acessórios }\end{array}$ & 32.8 & 32.5 & 25.1 & 23.2 \\
\hline Material de transporte & 9.6 & 14.5 & 13.0 & 9.8 \\
\hline $\begin{array}{l}\text { Instrumentos e aparelhos de óptica, fotografia ou } \\
\text { cinematografia, medida, controle ou de precisão; instrumentos } \\
\text { e aparelhos médico-cirúrgicos; aparelhos de relojoaria; } \\
\text { instrumentos musicais; suas partes e acessórios }\end{array}$ & & & & \\
\hline Armas e munições; suas partes e acessórios & 4.1 & 3.5 & 2.7 & 3.0 \\
\hline Mercadorias e produtos diversos & 0.1 & 0.2 & 0.2 & 0.2 \\
\hline Objetos de arte, de coleção e antiguidades & 1.0 & 1.2 & 1.8 & 1.2 \\
\hline
\end{tabular}

FONTE: MDIC

Nessa diversidade de produtos, entre os quais alguns homogêneos ou de baixo nível de processamento, a exemplo de minerais, borracha, plásticos, produtos do reino vegetal, alimentos e outros, aqueles de maior densidade tecnológica, oriundos das indústrias química, de máquinas, aparelhos e material elétrico, e de material de transporte ainda detém, no seu conjunto, a maior parcela do comércio bilateral. Tendo por base o peso e as características tecnológicas e comerciais dessas indústrias, a atenção estará concentrada na evolução dos capítulos que as compõem, mais especificamente aqueles com índices superiores a 0,5. Para tanto, visando diluir as eventuais oscilações anuais, causadas por circunstâncias dos mercados e da relação cambial, optou-se por calcular os índices G\&L médios trienais para esses três setores (Quadro 2).

QUADRO 2. ÍNDICE G\&L TRIENAL DAS SEÇÕES MAIS REPRESENTATIVAS - MÉDIAS TRIENAIS DE 1997-2008.

\begin{tabular}{|c|c|c|c|}
\hline Triênio & $\begin{array}{c}\text { Produtos das } \\
\text { indústrias químicas ou } \\
\text { das indústrias } \\
\text { conexas }\end{array}$ & $\begin{array}{c}\text { Máquinas e } \\
\text { aparelhos, } \\
\text { material elétrico, } \\
\text { e suas partes }\end{array}$ & $\begin{array}{c}\text { Material de } \\
\text { transporte }\end{array}$ \\
\hline $1997 / 99$ & 0,62 & 0,58 & 0,80 \\
\hline $2000 / 02$ & 0,73 & 0,63 & 0,66 \\
\hline $2003 / 05$ & 0,73 & 0,93 & 0,72 \\
\hline $2006 / 08$ & 0,80 & 0,76 & 0,99 \\
\hline
\end{tabular}

FONTE: Alice Web - Elaboração própria

Os resultados apresentados acima não diferem, na essência, daqueles obtidos por Hidalgo (1993), mostrando um crescimento em mais de três vezes do comércio intraindustrial entre os anos de 1967, 1978 e 1987, nos quais destacaram-se, igualmente, as mesmas indústrias. Considerando os aspectos 
relativos à internacionalização da indústria, a tendência de economias emergentes, como a brasileira, de se afastar da posição prévia de exportador de commodities, típica de comércio interindustrial, é fortalecida (OECD 2002). Assim é que, como sugerido na moldura teórica do comércio intraindustrial, é de se esperar que seus índices sejam mais elevados naqueles segmentos de maior complexidade tecnológica. O comércio bilateral entre Brasil - Estados Unidos, permite constatar essa tendência ao mostrar índices G\&L elevados nas indústrias destacadas acima.

As evidências acima apresentadas reforçam, portanto, a hipótese, inerente ao conceito de comércio intraindustrial, de que índices G\&L tendem a ser mais elevados naqueles setores mais desenvolvidos tecnologicamente, os quais abrangem em torno de $45 \%$ da corrente de comércio ao longo do período. Nesse caso, embora algumas indústrias tradicionais, como plásticos, borrachas, calçados e alimentos, tenham apresentado, em alguns anos, índices médios superiores a 0,5 , sua participação na corrente de comércio praticamente se manteve pouco expressiva ao longo do período. Por outro lado, é significativo o fato das seções compostas por indústrias mais complexas, produzindo, por exemplo, reatores nucleares, caldeiras, máquinas, aparelhos e instrumentos mecânicos, aparelhos e materiais elétricos, aparelhos de som e imagem, veículos e equipamentos de transporte aéreo e terrestre, apresentarem índices mais elevados.

Embora vários capítulos (dois dígitos) apresentem índices G\&L elevados, apenas seis deles ${ }^{5}$ são importantes na corrente de comércio em termos de valor. Entende-se ser irrelevante um alto índice G\&L em setores cujas participações no comércio é insignificante. Tomando o capítulo 84, nota-se uma combinação de elevada parcela do comércio com índice G\&L alto, revelando uma dinâmica de complementaridade entre as duas economias. Isso pode ser explicado pelas estratégias das empresas em termos de investimento direto, e consequente comércio intrafirma mais intenso, no bojo da internacionalização das cadeias produtivas em curso no período recente.

Essa parcela de produtos de elevados índices G\&L sugere significativas relações comerciais pautadas por fatores dinâmicos como inovação, economias de escala e diferenciação do produto. Dada sua importância em termos de valor e grau de sofisticação, observa-se no quadro 3 a incidência de comércio intraindustrial num patamar acima de um G\&L de 0,5. Assim, nos anos em que não há registro o padrão de comércio assume-se que as transações são mais tipicamente interindustrial.

584 (Reatores nucleares, caldeiras, máquinas, aparelhos e instrumentos mecânicos, e suas partes), 85 (Máquinas, aparelhos e materiais elétricos, e suas partes; aparelhos de gravação ou de reprodução de som, aparelhos de gravação ou de reprodução de imagens e de som em televisão, e suas partes e acessórios), 27 (Combustíveis minerais, óleos minerais e produtos de sua destilação; matérias betuminosa; ceras minerais), 87 (Veículos automóveis, tratores, ciclos e outros veículos terrestres, suas partes e acessórios), 88 (Aeronaves e aparelhos especiais e suas partes) e 40 (Borracha e suas obras). 
QUADRO 3. ÍNDICE G\&L DOS PRODUTOS DA INDÚSTRIA QUÍMICA, MÁQUINAS, APARELHOS E MATERIAL ELÉTRICO E MATERIAL DE TRANSPORTE, SUPERIORES A O,5 - MÉDIA TRIENAL

\begin{tabular}{|c|c|c|c|c|}
\hline \multicolumn{5}{|c|}{ Indústria Química } \\
\hline & $\begin{array}{l}1997 / \\
1999 \\
\end{array}$ & \begin{tabular}{|l|}
$2000 /$ \\
2002 \\
\end{tabular} & $\begin{array}{l}2003 / \\
2005\end{array}$ & \begin{tabular}{|l|}
$2006 /$ \\
2008 \\
\end{tabular} \\
\hline Combustiveis minerais,óleos minerais,etc.ceras minerais & 0.53 & 0.64 & 0.60 & - \\
\hline Produtos químicos inorgânicos,etc. & 0.66 & 0.71 & 0.76 & - \\
\hline Produtos químicos orgânicos & - & - & 0.54 & 0.87 \\
\hline Óleos essenciais e resinoides, prod. de perfumaria,etc. & 0.64 & 0.74 & 0.93 & 0.74 \\
\hline Matérias albuminoides, produtos a base de amidos,etc. & 0.65 & 0.76 & 0.96 & - \\
\hline Pólvoras e explosivos, artigos de pirotecnia,etc. & 0.62 & 0.82 & 0.60 & - \\
\hline \multicolumn{5}{|c|}{ Máquinas, aparelhos e mat. elétrico } \\
\hline Reatores nucleares, caldeiras, máquinas, etc.,mecânicos & 0.58 & 0.61 & 0.89 & 0.76 \\
\hline Máquinas, aparelhos e material elétrico e suas partes,etc & - & 0.66 & 0.97 & - \\
\hline \multicolumn{5}{|c|}{ Material de transporte } \\
\hline Veículos automóveis,tratores,etc.suas partes / acessórios & 0.96 & - & - & 0.99 \\
\hline Aeronaves e outros aparelhos aéreos,etc.e suas partes & 0.64 & - & - & - \\
\hline Veículos e material para vias férreas,semelhantes,etc. & - & 0.62 & 0.55 & - \\
\hline Embarcações e estruturas flutuantes & - & 0.70 & 0.90 & - \\
\hline
\end{tabular}

FONTE: MDIC

Ao se utilizar dados desagregados e mais específicos, o padrão de comércio resultante revela uma simultaneidade de relações intraindustriais com aquelas de caráter interindustrial. Em outras palavras, como ilustrado pelos produtos dos capítulos 84 e 85 da NCM, definido por um tipo de indústria ou atividade - Reatores nucleares, caldeiras, máquinas, aparelhos e instrumentos mecânicos, e suas partes - apresenta elevado índice G\&L, indicando que dentro deste grupo ocorrem trocas de produtos de uma mesma indústria. Ao se utilizar quatro dígitos, os índices permanecem elevados, mas na medida em que os dados são desagregados os índices tornam-se menores e de baixo significado. A desagregação a quatro dígitos resulta, assim, inevitável e logicamente, num comércio do tipo interindustrial, no qual os países se tornam mais complementares, a partir de trocas de produtos diferentes, no interior da mesma indústria, como parte de relações intrafirma.

Deduz-se, portanto, que quanto menos desagregados os dados, maior é a intensidade do comércio intraindustrial. Observando os produtos de maneira mais especifica, a intensidade do comércio intraindustrial tende a diminuir, aproximando-se de relações interindustriais. Ou seja, relações em que o Brasil exporta em maior quantidade um tipo ou parte de produto (por exemplo, transformador de dielétrico líquido), e importa dos EUA outro tipo ou parte de produto (por exemplo, outras partes de outros transformadores e conversores), o comércio será tipicamente interindustrial, embora estes produtos sejam de uma mesma indústria ou atividade - materiais elétricos. No nível de atividade, os fluxos de comércio podem ser caracterizados, de forma geral, como intraindustriais. 
Na verdade, as evidências apresentadas reforçam os argumentos de Fontagné e Freudenberg (1997) a respeito do índice de Grubel Lloyd, segundo a qual parte do comércio intraindustrial pode ser apenas aparente em consequência de uma desagregação insuficiente de dados. Ou seja, aqueles capítulos nos quais predominam produtos homogêneos e de baixo valor agregado, comportam relações comerciais caracterizadas por um padrão de comércio interindustrial, em que o Brasil exporta, mais do que importa, produtos menos complexos. A desagregação dos dados pode evidenciar este resultado, demonstrando a coexistência do comércio intraindustrial com um padrão de comércio interindustrial. De qualquer forma, o comércio entre os dois países reflete uma tendência de aproximação de suas indústrias, mesmo que trocas tipicamente interindustriais ainda façam parte de suas trocas.

\section{Conclusão}

A partir de 1979, além dos produtos básicos, o Brasil passou a exportar predominantemente produtos manufaturados aos Estados Unidos, mesmo que marcados por dotações relativas de capital/trabalho diferentes. No entanto, a emergência de uma indústria mais desenvolvida e globalizada contribuiu para uma mudança qualitativa nas relações comerciais entre os dois países, conduzindo-as gradativamente na direção de um padrão de comércio intraindustrial. Teoricamente este tipo de comércio pode ser explicado pela existência de economias internas e externas, diferenciação do produto e inovação, semelhança no tamanho do mercado interno e em níveis de renda. Ao contrário do comércio interindustrial, em que os determinantes do comércio são dados por vantagens comparativas de custo ou de dotação de recursos.

Tendo por base os dados analisados, constatou-se que a maior parte do comércio entre esses dois países é marcada por trocas de produtos industriais intermediários, ou seja, produtos e suas partes, que são utilizados na produção de outros produtos. Apesar de uma parcela significativa de produtos apresentar elevados índices de comércio intraindustrial, um grande número de produtos ainda é marcado por índices Grubel Lloyd reduzidos. Por outro lado, mesmo diante de uma grande diversificação da corrente de comércio entre Brasil e EUA alguns capítulos de produtos se destacam, seis dos quais apresentam índices maiores ou iguais a 0,7.

Portanto, mesmo que o comércio entre Brasil e Estados Unidos tenha sido construído através de uma forte complementaridade na forma de relações Norte - Sul, no período recente ocorreu uma reversão dos seus termos de troca. A maior integração da economia global, alimentada por fluxos mais intensos de investimento direto estrangeiro, alterou as estratégias das empresas, em função das quais o comércio intrafirma e as trocas de componentes de produtos mais sofisticados ganharam maior importância, como observado 
nas evidências relativas às indústrias destacadas nesta análise. Sendo assim, considerando o nível da atividade industrial, vista a dois dígitos, o padrão de comércio intraindustrial se destacou nos últimos anos. Mesmo que simultaneamente às trocas interindustriais de produtos industriais complementares. Portanto, embora as evidências aqui apresentadas reafirmem as limitações dos conceitos associados ao padrão de comércio, elas sugerem, por outro lado, a necessidade de se reinterpretar as trocas de produtos no interior de uma indústria à luz da nova geografia da produção industrial e da economia mundial como um todo.

\section{Referências}

CALDARELLI, C. E. \& MIRANDA, SÍlVIA H. G. DE (2009). "Restrições comerciais e comércio intra-industrial: uma análise usando modelo LOGIT". In $47^{\circ}$. Congresso da SOBER, 2009, Porto Alegre.

DOSI, G. \& PAVITT, K. \& SOETE, L. (1990). The Economics of Technical Change and International Trade. $1^{\mathrm{a}}$ ed. Hertfordshire: Harvester Wheatsheaf.

FONTAGNÉ, L. \& FREUDENBERG, M. (1997). Intra-Industry Trade: Methodological Issues Reconsidered, CEPII, document de travail nº 97-01, Centre D’Études Prospectives et D’Informations Internationales.

FUNDAÇÃO CENTRO DE ESTUDOS DO COMÉRCIO EXTERIOR. Base de dados. URL: <http://www.funcex.com.br/basesbd/cad_base.asp?tp=1>. Acesso em: 27 de outubro de 2008.

GREENAWAY, D. \& WINTERS A. L. (1994). (ed.). Surveys in International Trade. $1^{\mathrm{a}}$ ed. Cambridge: Blackwell.

GREENAWAY, D. \& THARAKAN, P. K. M. (1986). (ed.). Imperfect Competition and International Trade. $1^{\mathrm{a}}$ ed. Sussex: Wheatsheaf Books.

GRUBEL, H. G. \& LLOYD, P. J. (1975). Intra-Industry trade: the theory and measurement of international trade in differentiated droducts. London: Macmillan.

HELPMAN, E. (1987) "Imperfect competition and international trade: evidence from fourteen industrialized countries". Journal of the Japanese and International Economies, 1, June, 62-81.

HIDALGO, A. B. (1993). "Mudanças na estrutura do comércio internacional brasileiro: comércio interindústria x comércio intra-indústria”, Análise Econômica, UFRGS, 11(20): 55-68.

KRUGMAN, P. (1980). "Scale economies, product differentiation and the pattern of trade”, American Economic Review, 70: 469-479.

KRUGMAN, P. (1981). "Intra-industry specialization and the gains from trade, Journal of Polical Economy”, 89: 959-973.

KRUGMAN, P. (1993) Empirical evidence on the New Trade Theories: the current state of, Report for Centro Studi sui Processi di Internazionalizzazione (CESPRI) at Bocconi, University in Milan. p. 11-31.

KRUGMAN, P. (1994). Rethinking International Trade. $4^{\mathrm{a}}$ ed. Cambridge: Massa- 
chusetts Institute of Technology.

LINDER, S. (1961). An Essay on Trade an Transformation. New York: John Wiley.

LOERTSCHER, R. \& WOLTER, F. (1980). "Determinants of intra-industry trade: among countries and across countries”. Weltwirtschaftliches Archiv, 116: 280293.

MARKUNSEN, J. R. \& VENABLES, A. J. (2000). The theory of endowment, intraindustry and multi-national trade, Journal of International Economics, 52: 209-234.

MINISTÉRIO DO DESENVOLVIMENTO, INDÚSTRIA E COMÉRCIO EXTERIOR (MDIC). Estatísticas de comércio exterior. URL: <http://www.desenvolvimento. gov.br/sitio/interna/index.php?area=5>. Acesso em: 27 de outubro de 2008.

MINISTÉRIO DO DESENVOLVIMENTO, INDÚSTRIA E COMÉRCIO EXTERIOR. Códigos e Descrições - NCM . URL: <http://www.desenvolvimento.gov.br/ sitio/interna/interna.php? area $=5 \&$ menu $=1095 \&$ refr $=605>$. Acesso em: $27 \mathrm{de}$ outubro de 2008.

OECD (2002)., "Intra-industry and intra-firm trade and the internationalisation of production", Economic Outlook, chapter V, p. 160-170.

SAVASINI, J. A. A et al. (1979). (org.). Economia Internacional. São Paulo: Saraiva. SECRETARIA DO COMÉRCIO EXTERIOR. “Alice Web”. URL:

< http://aliceweb.desenvolvimento.gov.br/ > . Acesso em: 27 de outubro de 2008.

SILVA, M. Padrão de especialização no comércio bilateral argentina - brasil no período 1989-200o: uma ênfase no comércio intra-indústria, Dissertação de Mestrado em Integração Latino-Americana, PPGMILA/UFSM, RS.

VASCONCELOS, C. R. F.(2003). “O Comércio Brasil-Mercosul na década de 90: uma análise pela ótica do comércio intra-indústria”. Rev. Bras. Econ., 57(1) Rio de Janeiro. URL: <http://www.scielo.br/scielo.php?pid=Soo34$71402003000100012 \&$ script $=$ sci_arttext\&tlng=en $>$. Acesso em: 27 de outubro de 2008.

VERNON, R. (1966). International Investment and International Trade in the Product Cycle. Quarterly Journal of Economics, May.

WORLD TRADE ORGANIZATION. Statistics. URL:

< http://www.wto.org/english/res_e/statis_e/statis_e.htm>. Acesso em: 27 de outubro de 2008.

Recebido em: 01 de setembro de 2009 Primeira resposta em: 02 de dezembro de 2009 Aceite em: 27 de janeiro de 2010 
